\title{
Vogt-Koyanagi-Harada syndrome: a discussion about resistance to corticotherapy
}

\author{
Vogt-Koyanagi-Harada: uma discussão sobre resistência à corticoterapia
}

Natália de Carvalho Dias ${ }^{1}$ (i), Camila V. Ventura ${ }^{2}$ (])

Keywords:

Vogt-Koyanagi-Harada syndrome; Uveitis; Retinal detachment; Steroids; Pulse therapy, drug

Descritores:

Doença de Vogt-KoyanagiHarada; Uveíte; Descolamento da retina; Esteroides;

Pulsoterapia

$$
\begin{array}{r}
\text { Received on: } \\
\text { Aug 8, } 2020 \\
\text { Accepted on: } \\
\text { Apr 3, 2021 } \\
\text { Corresponding author: } \\
\text { Camila V. Ventura } \\
\text { Fundação Altino Ventura } \\
\text { Rua da Soledade, } 170 \text { - Soledade } \\
\text { Zip code 50070-040 - Recife, PE, Brazil } \\
\text { E-mail: camilaventuramd@gmail.com } \\
\text { Institution: } \\
\text { Fundação Altino Ventura, Recife, PE, Brazil. } \\
\text { Conflict of interest: } \\
\text { no conflict of interest. } \\
\text { Financial support: } \\
\text { for this work. } \\
\text { the authors received no financial support } \\
\text { Meeting presentation: } \\
\text { the present case was presented at the } \\
22^{\circ} \text { Congresso Norte e Nordeste de } \\
\text { Oftalmologia. }
\end{array}
$$

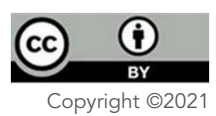

\section{ABSTRACT}

Vogt-Koyanagi-Harada (VKH) syndrome is an inflammatory condition of unknown etiology that can affect the eye. The most common ocular manifestation related to VKH is bilateral diffuse uveitis associated to exudative retinal detachment. Although these patients respond well to steroid pulse therapy, we report a case of a 44-year-old female patient presenting bilateral exudative retinal detachment and clinical diagnosis of $\mathrm{VKH}$, who did not respond to the first cycle of 3-day pulse therapy with methylprednisolone. The exudation was reabsorbed only after a second cycle of steroid therapy.

\section{RESUMO}

A doença de Vogt-Koyanagi-Harada é inflamatória e de etiologia desconhecida, podendo afetar o olho. A manifestação ocular mais comum relacionada à doença de Vogt-Koyanagi-Harada é a uveíte difusa bilateral associada ao descolamento exsudativo da retina. Embora esses pacientes respondam bem à pulsoterapia com esteroides, relatamos um caso de paciente de 44 anos que apresentou descolamento exsudativo bilateral da retina com diagnóstico clínico de doença de Vogt-Koyanagi-Harada que não respondeu ao primeiro ciclo de pulsoterapia de 3 dias com metilprednisolona. A exsudação apenas reabsorveu após uma segunda rodada de terapia com esteroides. 


\section{INTRODUCTION}

Vogt-Koyanagi-Harada (VKH) syndrome (uveomeningoencephalitic syndrome) is a rare autoimmune, multisystemic disease that involves melanin-containing tissues. It is characterized by bilateral, chronic panuveitis, associated with variable manifestations of neurological, auditory, and skin involvement. ${ }^{(1)}$

It occurs mainly in females and young adults (second to fourth decade), although it can affect from childhood to adulthood (10 to 50 years), with a peak in frequency in the third decade. ${ }^{(1-3)}$

The development of VKH disease has not been completely understood yet, but apparently it is triggered by an environmental exposure in a person with a genetic predisposition to the disease. Additional research in this area is needed to understand the complex interplay between genetics, environment, and the immune response in $\mathrm{VKH}$ patients. ${ }^{(4)}$

The most common ocular symptom is bilateral blurred vision, and other findings include eye pain, photophobia, conjunctival hyperemia, reduced visual acuity and even total vision loss. . $^{(3-5)}$ Ocular changes are characterized by bilateral posterior uveitis with retinal edema, hyperemia, or edema of the optic disc and retinal detachment. ${ }^{(2,5)}$

The use of ever-evolving imaging technology has allowed better visualization and understanding of the underlying disease process in eyes with VKH. Fluorescein angiography (FA) is one of the oldest and most widely used imaging modalities for this disease. However, with the advent of the high-resolution imaging provided by optical coherence tomography (OCT), subretinal fluid and serous detachments in eyes with acute VKH are easily identified. ${ }^{(6)}$ In addition to visualization of exudative retinal detachment, it also allows visualizing folds in the retinal pigment epithelium (RPE), and increased choroidal thickness, which are commonly observed in the acute phase of disease. ${ }^{(7)}$

The clinical course of the disease is variable, from a limited period of intraocular inflammation with rapid depigmentation to a chronic, prolonged, and recurrent disease, requiring treatment with high-dose steroid therapy and with a poor visual prognosis, if not timely treated. ${ }^{(4,5)}$

\section{CASE REPORT}

A 44-year-old female patient was admitted to the emergency department of Fundação Altino Ventura, in Recife (PE), Brazil, with the chief complaint of sudden vision loss in the right eye (OD). She denied comorbidities or other systemic symptoms. The ophthalmological examination revealed a slightly reduced pupillary light reflex in $\mathrm{OD}$, with no relative afferent pupillary defect. The best-corrected visual acuity (BCVA) in OD was 20/150 and in the left eye (OS) was 20/30. The intraocular pressure (IOP) was $12 \mathrm{mmHg}(\mathrm{OD})$ and $15 \mathrm{mmHg}(\mathrm{OS})$. The slit-lamp examination of the anterior segment was normal with no signs of active or past uveitis. Fundus examination revealed a hyperemic optic disc and a white-yellowish retinal detachment affecting the macula and extending to the superior temporal arcade. No alterations were identified in OS. The patient was asked to return the following day to be examined by a retina/uveitis specialist.

The patient returned one day later complaining of vision loss in OS. The BCVA on day 2 was 20/150 in OD and $20 / 80$ in OS. The fundus examination of OD was maintained; however, OS presented similar findings (Figures $1 \mathrm{~A}$ and $1 \mathrm{~B})$. Ancillary exams for infectious diseases including serologies for syphilis (FTA-Abs and VDRL), HIV, tuberculosis and toxoplasmosis, chest X-ray and Mantoux test were ordered, as well as fundus imaging. The OCT (RTVue-10o SD-OCT, Optovue Inc., Fremont, CA) revealed exudative retinal detachment in both eyes (OU) (Figures $2 \mathrm{~A}$ and $2 \mathrm{~B}$ ). Fluorescein angiography (FA) showed a hyperfluorescent optic disc and presence of diffuse hyperfluorescent pinpoints (Figures 2C and 2D).

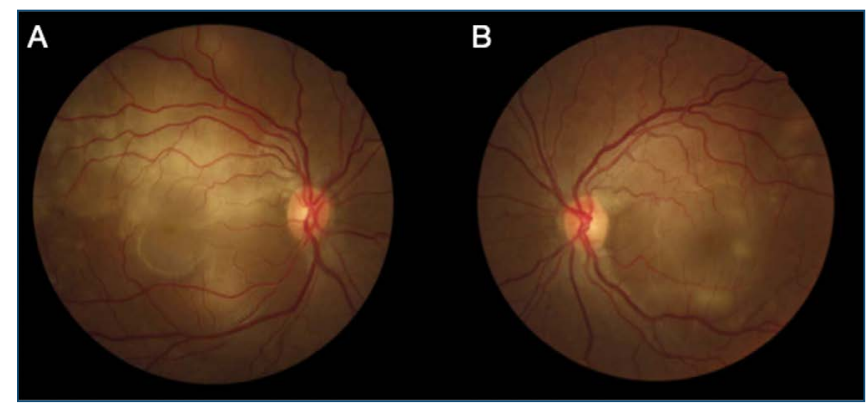

Figure 1. Color fundus images of the right eye (A) and left eye (B) in the initial assessment at the retina/uveitis department.

On day 3, the patient presented a worsening of the BCVA of counting fingers at $30 \mathrm{~cm}$ in OU. The serology results for syphilis, HIV, toxoplasmosis, and tuberculosis were negative. The clinical diagnosis of VKH was made and the patient was submitted to pulse therapy with methylprednisolone $1 \mathrm{~g} /$ day for 3 days.

After completing pulse therapy, the patient returned to the follow-up visit complaining of a worsening of the vision in OU, headache, and a tickling sensation in her ears. The ophthalmological examination revealed a BCVA of hand movement in OU. Funduscopy, FA, and OCT exams showed worsening of the exudative retinal detachment 

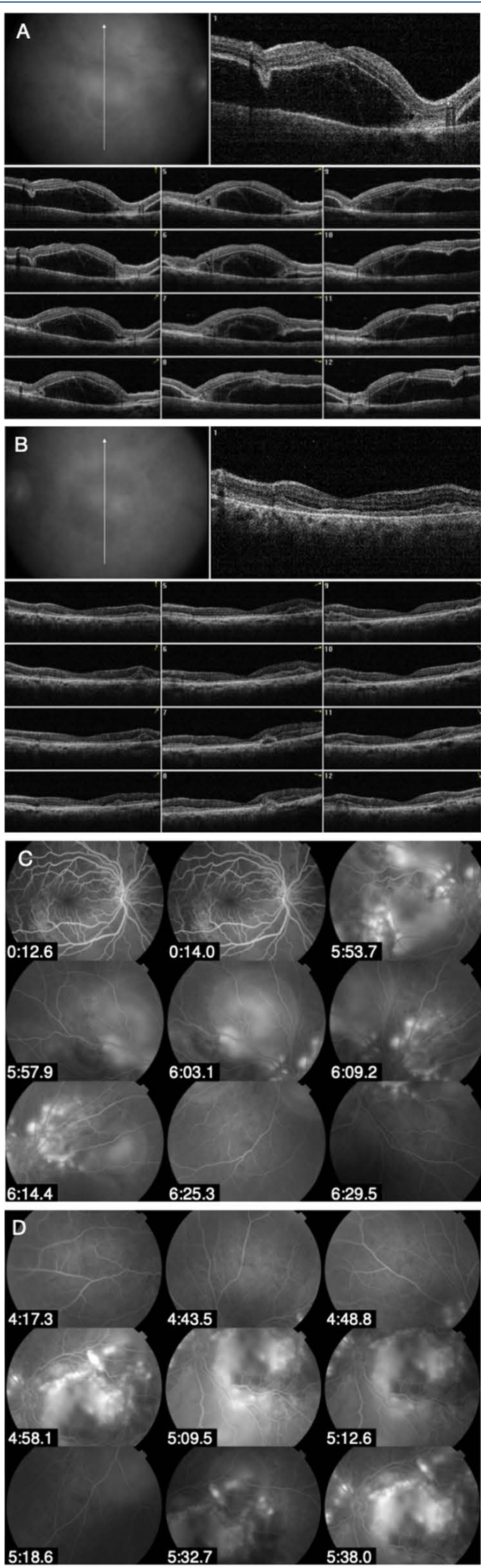

Figure 2. Macular optical coherence tomography images of the right eye (A) and left eye (B) upon initial examination, and FA images of both eyes, respectively (C, D). (B) Upon initial examination and FA images of both eyes, respectively $(C, D)$. extending to the mid periphery in OU. The decision was to try a second cycle of pulse therapy with methylprednisolone 1 g/day.

After completing the second cycle of pulse therapy, 14 days after her initial admission to the emergency room, the patient presented significant improvement. Her BCVA in OU was 20/60 and fundus examination in OU showed diffuse pigmentary mottling of the RPE and improvement in exudative retinal detachment (Figures 3A and 3B). Oral prednisone initially prescribed at a dose of $1 \mathrm{mg} / \mathrm{kg} /$ day after the two pulse therapies was tapered weekly.

This case report was approved by the Institutional Review Board of Ethics in Research at the Altino Ventura Foundation (FAV) - Protocol number: 4.183.069
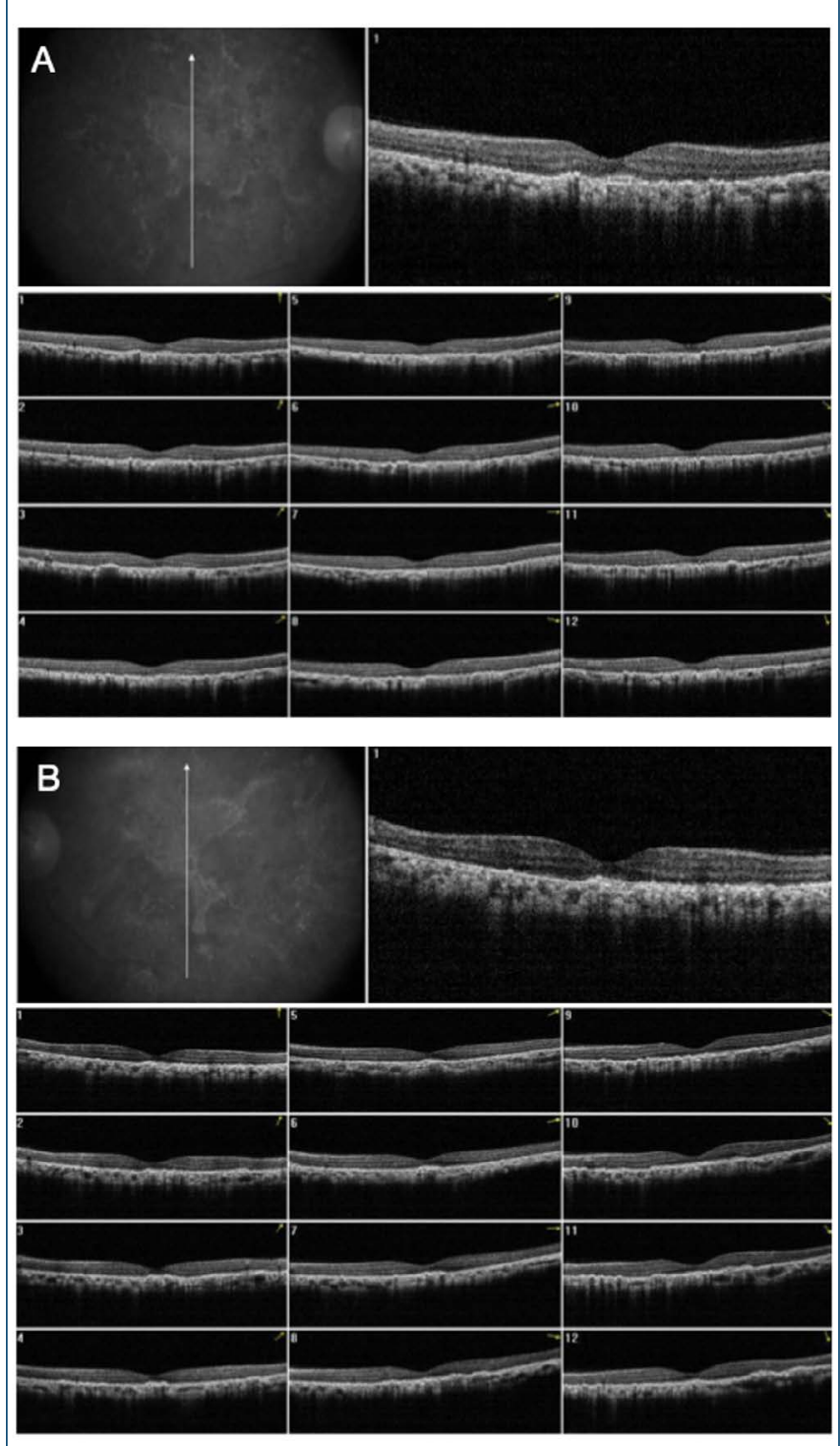

Figure 3. Macular optical coherence tomography images of the right eye $(A)$ and left eye $(B)$ upon initial examination. 


\section{DISCUSSION}

Vogt-Koyanagi-Harada syndrome, a multisystemic inflammatory condition, requires prompt treatment initiation to minimize secondary complications and vision loss. ${ }^{(8)}$ The treatment of VKH most commonly involves corticosteroids in the acute phase of the disease. Immunomodulatory therapy may be initiated for patients with incomplete response to corticosteroids alone, or in cases that require unacceptably high dose of corticosteroids to be controlled. For such cases, different types of medications and classes of immunomodulatory therapy have been used, including classic antimetabolites, such as T-cell inhibitors and biologic agents, both requiring careful pretreatment evaluation and close monitoring while on use. ${ }^{(9)}$

The patient described presented typical signs of $\mathrm{VKH}$ and after ruling out other infectious diseases, such as HIV, syphilis and tuberculosis, corticosteroid pulse therapy was initiated. Nevertheless, the patient presented resistance to treatment and progressed with worsening of VA and retinal detachment in both eyes. Glucocorticoid resistance can be defined as absence of inflammatory improvement, persistence or worsening of inflammation, as described by standardization of uveitis nomenclature and/or persistence of retinal detachment, and was identified in this case. ${ }^{(10)}$

However, it is important to note that, in Brazil, it is exceedingly difficult to have a group of patients with homogeneous racial characteristics due to miscegenation. Hence, it is quite difficult for patients to meet all diagnostic criteria, contrary to what is observed in the Japanese evaluations. This fact has been well explained in the literature. ${ }^{(11)}$

Since up to one third of VKH patients present no response to initial steroid pulse therapy, studies are currently trying to understand why some patients with $\mathrm{VKH}$ are resistant to treatment with pulse therapy, and require another cycle of pulse therapy or immunosuppressive therapy. ${ }^{(8)}$ The role of glucocorticoid receptor in peripheral blood as a biomarker of resistance could be a clinical predictive factor of non-responsiveness of these patients to pulse therapy, and has already been investigated. ${ }^{(8)}$
The continuous search to understand non-responsiveness of some patients to glucocorticoid therapy is necessary to better manage these patients, since time is an important factor to preserve vision in these cases.

In our case report, the patient responded well to the second pulse therapy cycle, 14 days after the initial assessment, and immunomodulatory therapy was not required. However, it is important to note that $25 \%$ to $50 \%$ of VKH patients present recurrence of the disease. ${ }^{(12,13)}$ Thus, slow tapering of the oral steroid and close monitoring of the patient is needed.

\section{REFERENCES}

1. Herbort CP, Mochizuki M. Vogt-Koyanagi-Harada disease: inquiry into the genesis of a disease name in the historical context of Switzerland and Japan. Int Ophthalmol. 2007;27(2-3):67-79.

2. Nussenblatt R, Whitcup $S$, Palestine A. Vogt-Koyanagi Harada Syndrome. Uveitis. fundamentals and clinical practice. St Louis: Mosby; 1996. p. 312 24.

3. Al-Kharashi AS, Aldibhi H, Al-Fraykh H, Kangave D, Abu El-Asrar AM Prognostic factors in Vogt-Koyanagi-Harada disease. Int Ophthalmol. 2007;27(2-3):201-10.

4. Rao NA, Sukavatcharin S, Tsai JH. Vogt-Koyanagi-Harada disease diagnostic criteria. Int Ophthalmol. 2007;27(2-3):195-9.

5. Rao NA. Pathology of Vogt-Koyanagi-Harada disease. Int Ophthalmol. 2007;27(2-3):81-5.

6. Ishihara K, Hangai M, Kita M, Yoshimura N. Acute Vogt-Koyanagi-Harada disease in enhanced spectral-domain optical coherence tomography. Ophthalmology. 2009;116(9):1799-807.

7. Burkholder BM. Vogt-Koyanagi-Harada disease. Curr Opin Ophthalmol. 2015;26(6):506-11.

8. Sugita S, Takase H, Kawaguchi T, Taguchi C, Mochizuki M. Cross-reaction between tyrosinase peptides and cytomegalovirus antigen by $T$ cells from patients with Vogt-Koyanagi-Harada disease. Int Ophthalmol. 2007;27(23):87-95.

9. Urzua CA, Guerrero J, Gatica H, Velasquez V, Goecke A. Evaluation of the glucocorticoid receptor as a biomarker of treatment response in VogtKoyanagi-Harada disease. Invest Ophthalmol Vis Sci. 2017;58(2):974-80.

10. Jabs DA, Nussenblatt RB, Rosenbaum JT; Standardization of Uveitis Nomenclature (SUN) Working Group. Standardization of uveitis nomenclature for reporting clinical data. Results of the First International Workshop. Am J Ophthalmol. 2005;140(3):509-16.

11. Cardoso IH, Zajdenweber ME, Muccioli C, Fimamor LP, Belfort R Jr. Applicability of the 2001 revised diagnostic criteria in Brazilian VogtKoyanagi-Harada disease patients. Arq Bras Oftalmol. 2008;71(1):67-70.

12. Iwahashi C, Okuno K, Hashida N, Nakai K, Ohguro N, Nishida K. Incidence and clinical features of recurrent Vogt-Koyanagi-Harada disease in Japanese individuals. Jpn J Ophthalmol. 2015;59(3):157-63.

13. Maruyama K, Noguchi A, Shimizu A, Shiga Y, Kunikata H, Nakazawa T. Predictors of recurrence in Vogt-Koyanagi-Harada disease. Ophthalmol Retina. 2018;2(4):343-50. 